\title{
Hand-Held Self-Monitoring Blood Cholesterol Devices for the Monitoring of Patients
}

\author{
Bolodeoku J* \\ Department of Cardiology, UK
}

*Corresponding author: Bolodeoku J, Lipid Clinic, Cardiology Department, Sherborne Building, Hampshire Hospital NHS Foundation Trust, Aldermaston Road, Basingstoke, Hampshire. RG24 7AN, United Kingdom

\section{ARTICLE INFO}

Received: 㓞 December 03, 2019

Published: December 13, 2019

\section{ABSTRACT}

Abbreviations: POCT: Point of Care Testing; GP: General Practice; SMBC: Self-Monitoring of Blood Cholesterol; POC: Point-of-Care; TC: Total Cholesterol; TG: Triglyceride; CRMLN: Cholesterol Reference Method Laboratory

Citation: Bolodeoku J. Hand-Held Self-Monitoring Blood Cholesterol Devices for the Monitoring of Patients. Biomed J Sci \& Tech Res 23(5)-2019. BJSTR. MS.ID.003967.

\section{Introduction}

A

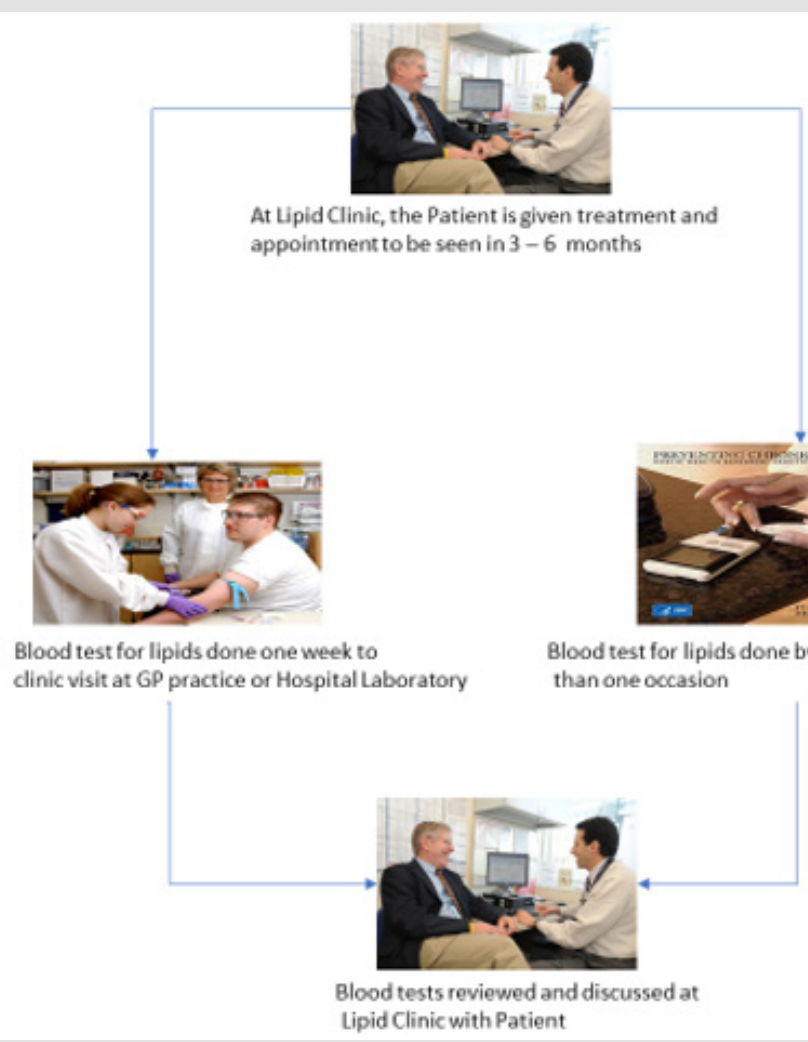

B

Figure 1: Showing routes A and B in the monitoring of blood cholesterol in a lipid clinic. 
Point of Care Testing (POCT) in the monitoring of hypertensive and diabetic patients for blood pressure and glucose has been shown to be beneficial [1-8]. In the management of patients with hyperlipidaemia, it is the normal practice that after initiating pharmacological interventions such as statins, fibrates, bile acid sequestrants and more recently, PCSK9 inhibitors, the patients are expected to have a follow up laboratory test done at some appropriate time point. Patients will usually have these blood tests done at the local hospital laboratory or General Practice (GP) who would have the blood sample sent to the local hospital laboratory prior to their visit in order to have the cholesterol estimations ready for their out-patient visit. This way of conducting blood cholesterol measurements is not optimum as most clinicians are usually making a judgement call on one blood lipid profile estimation when the more optimum procedure will be to make the call after a review of more than one lipid profile. This would require the patients to attend the local hospital laboratory or General Practice (GP) at least more than once see-route A in (Figure 1), this could be quite a bother to patients and therefore the question is can portable hand-held self-monitoring of blood cholesterol (SMBC) see-route B in (Figure 1) be of benefit in the management of these patients.

The POCT devices for measuring cholesterol vary from hand-held self-monitoring blood cholesterol devices such as the Accutrend Plus, Bene Check Plus, CardioChek PA, Cholestech LDX ${ }^{\circledR}$, Veri-Q, 3 in 1, the elemark ${ }^{\mathrm{TM}}$, to the compact desktop analyser such as the Cholestech LDX ${ }^{\circledR}$. They measure a number of lipid fractions (total cholesterol, triglycerides, high density lipoprotein, low density lipoprotein) and ratios on whole blood, plasma or serum collected from the finger or venous blood using reflectance or biosensor technology with single-use, disposable, dry reagent test strips, rotors or cassettes. The Cholestech LDX is one of the wellstudied lipid testing POCT devices but it is a desk top analyser, this review focuses on the portable handheld self-testing devices such as the Accutrend Plus, BeneCheck Plus, CardioChek PA, Veri-Q 3in1 and the elemark. There are several factors that should be considered that will influence the lipid estimations such as the accuracy, the precision and practical usage of the devices and the person day to day lipids variation. These factors will be discussed in relation to several of the portable hand-held self-monitoring blood cholesterol devices on the market and in the literature $[9,10]$.

\section{Accuracy}

The CardioChek PA was one of the two point-of-care (POC) cholesterol testing devices that was directly compared to a laboratory method using a venous sample to determine device accuracy, the conclusion was that the device produced clinically equivalent values when compared to the same patients' samples analyzed in a reference laboratory and operated within industry accuracy standards $[11,12]$. The Accutrend ${ }^{\circledR}$ Plus total cholesterol (TC) and triglyceride (TG) concentrations correlated very well ( $\mathrm{r}$ $>0.80$ ) with laboratory reference method used [13]. Recently, TC, and TG results from the elemark ${ }^{\mathrm{TM}}$ device were shown to correlate very highly with those of laboratory method using the AU5800 Analyzer (Beckman Coulter Inc., IN, USA) [14].

\section{Precision}

The laboratory analytical precision is measured as coefficient of variation percent (CV\%). The Cholesterol Reference Method Laboratory (CRMLN) cholesterol certification criteria for total cholesterol (TC) is $<$ or $=3 \%$, for and high density lipoproteincholesterol (HDL-C) is $<$ or $=4 \%$ and for low density lipoproteincholesterol (LDL-C) $<$ or $=4 \%$ and HDL-C $<$ or $=4 \%$ and the National Cholesterol Education Programme (NCEP) recommended precision performance criteria for laboratory TC is $<$ or $=3 \%$ and HDL-C $<$ or $=6 \%[15,16]$. The precision for the Cardiochek PA, was $3.7 \%$ for total cholesterol and 6.2\% for HDL-C for level 1 concentration and 3.6\% for TC and 3.5\% for HDL-C for level 2 concentration [17]. In an evaluation by the UK NHS Purchasing and Supply Agency of the CardioChek PA, showed for TC an imprecision of 12\%, for HDLcholesterol $22 \%$ and for TG $14 \% 10$. In a recent study, it was shown that there was comparable precision between the FDA cleared, CE marked, CLIA waived and CRMLN certified CardioChek PA and the elemark $^{\mathrm{TM}}$. The lipid precision profile of both devices (CardioChek PA - 5.4 - 8.3\% for TC, 3.4\% - 5.5\% for HDL-C, 9.4\% - 14.0\% for LDL-C and elemark ${ }^{\mathrm{TM}}-3.0 \%-5.3 \%$ for TC, $4.3 \%-6.2 \%$ for HDL-C and $5.5 \%-14.4 \%$ for LDL-cholesterol)[18]. In addition, the interassay precision of the MultiCare Cholesterol system was $4.51 \%$ (range, 2.38\% - 8.54\%) for TC and 3.29\% (range, 1.06\% - 7.45\%) for TG [19].

\section{Biological Variation}

Lipid concentrations vary within the course of the day and the ranges of within person biological variability (expressed as the coefficient of variation percent) that have been described in the literature for healthy volunteers shows the $\mathrm{CV} \%$ ranges for total cholesterol is $2.5 \%-10.9 \%$, for HDL-cholesterol is $3.6 \%-12.4 \%$, for LDL-cholesterol $7.8 \%-13.6 \%$ and for triglyceride $12.9 \%$ $40.8 \%$ [20-23]. The within person day to day variation in a healthy volunteer was assessed using three of the cholesterol testing POCT devices, the 3in1, CardioChek PA and elemark ${ }^{\mathrm{TM}}$ and their respective CV\% fell within the CV\% described in the literature: for the 3in 1 , total cholesterol $6.9 \%$ and triglyceride $34 \%$; for the CardioChek PA, total cholesterol 9.4\%, triglyceride 23\% HDL-cholesterol 7.0\%, LDL-cholesterol $14 \%$ and triglyceride $23.11 \%$; for the elemark ${ }^{\mathrm{TM}}$ total cholesterol 5.0\%, triglyceride 30\% HDL-cholesterol 13\% and LDL-cholesterol 13\% see Figure 2 [24]. 


$$
\begin{aligned}
& 5.4-5.7>4.8-5.1-5.1-5.2-5-5.1-5-4.5-4.7-4.5 .0083333333 \\
& 0.7-0.8-0.6-1.3-0.8>^{1.6}-1-1.1-0.9-0.8-0.6-0.6-0.9 \\
& \begin{array}{lllllllllllll}
1 & 2 & 3 & 4 & 5 & 6 & 7 & 8 & 9 & 10 & 11 & 12 & \text { Mean }
\end{array} \\
& --\operatorname{3in} 1 \mathrm{TC}--\operatorname{3in} 1 \mathrm{TG}
\end{aligned}
$$

Note: $\operatorname{3in} 1$.

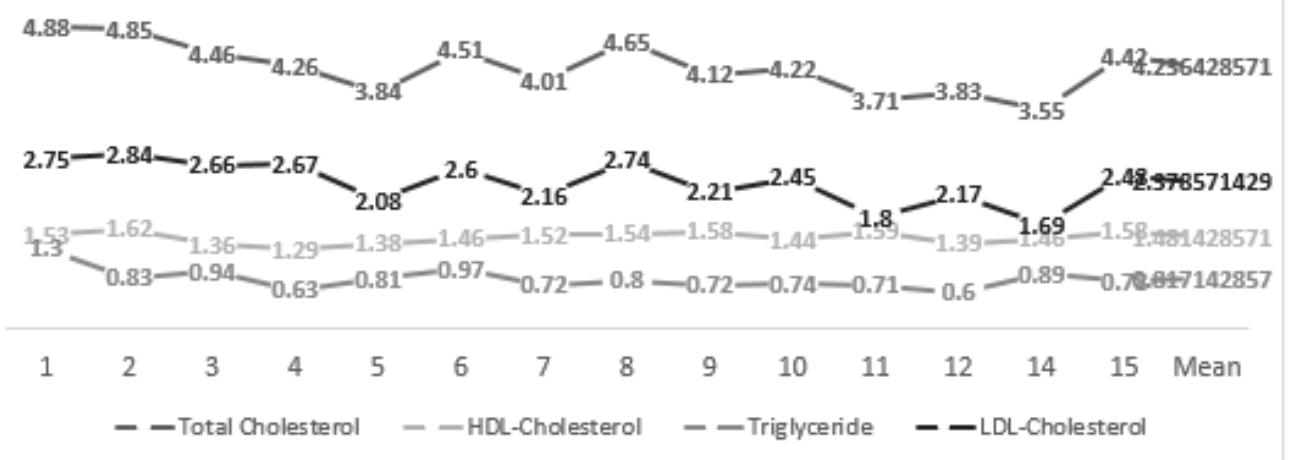

\section{Note: CardioChek PA.}

$$
\begin{aligned}
& 5.4-5.6-5.9-6.1>_{5.6}-5.7-6.4>_{5.5}-5.8-6-5.7-5.5-5.7-5.9>_{5.2}-5.8-5.73
\end{aligned}
$$

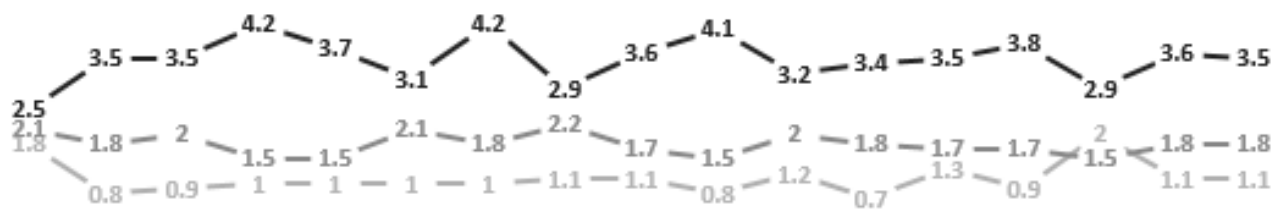

$$
\begin{aligned}
& \begin{array}{lllllllllllllllll}
1 & 2 & 3 & 4 & 5 & 6 & 7 & 8 & 9 & 10 & 11 & 12 & 13 & 14 & 15 & 16 & \text { Mean }
\end{array} \\
& \text { - - Total Cholesterol - - Triglyceride - -HDL-Cholesterol - - LDL-Cholesterol }
\end{aligned}
$$

\section{Note: Elemark ${ }^{m m}$}

Figure 2: Showing daily finger lipid measurements in healthy volunteer using 3in1, CardioChek PA and elemark ${ }^{\mathrm{TM}}$.

\section{Practical Usage}

The MultiCare system was easy to be used by patients, when their self-measured estimations of either total cholesterol or triglyceride were compared with the results of a professional operator performed on the same device on a second sample, there was very good correlation $(r=0.978)$ with a mean difference of $0.28 \%$ between the two sets of results [19]. In a randomized study, investigating the value of home monitoring of lipids, one group of patients received the hand-held device (CardioChek PA) and measured and reported their lipid levels for 6 months using a phone call, whilst the other group had their lipid measured in the usual care group in the traditional laboratory setting. The results showed that mean LDL-C decreased from $186 \mathrm{mg} / \mathrm{dL}$ (4.8 mmol/L) to $117 \mathrm{mg} / \mathrm{dL}$ ( $3.0 \mathrm{mmol} / \mathrm{L}$ ) in the usual care group, whilst, a similar reduction of LDL-C decrease from $162 \mathrm{mg} / \mathrm{dL}(4.2 \mathrm{mmol} / \mathrm{L})$ to $105 \mathrm{mg} / \mathrm{dL}$ (2.7 $\mathrm{mmol} / \mathrm{L}$ ) was observed in the patients using the home monitoring, there was no significant difference between the mean changes. In addition, there was also no significant difference between the two groups with regards to mean changes in HDL-C and triglycerides [25]. 


\section{Conclusion}

In conclusion, it appears that the portable hand-held selfmonitoring blood cholesterol devices correlate very well with the traditional laboratory cholesterol methods. Even though it appears that both the precision criteria (CRMLN and NCEP) are quite stringent for the portable hand-held self-monitoring blood cholesterol devices, as all of the devices exceeded the expected analytical precision for TC of $<$ or $=3 \%$, for HDL-C of $<$ or $=4 \% / 6 \%$ and for LDL-C of LDL-C $<$ or $=4 \%$, they have a reasonable precision profile and they can be used very well by patients. This review highlights the potential of self-monitoring hand-held devices to be used in the management of patients undergoing therapeutic intervention, where there is a requirement to monitor the lipid levels in response to the interventions. There is a need for more realworld experience in the use of these devices in the management of these patients in the primary and outpatient settings.

This would help to fully understand the true benefit and impact these devices have in the management of patients undergoing therapeutic intervention. As self-monitoring of blood glucose is routine in the management of patients with diabetes mellitus, self-monitoring of blood lipids will become routine in the management of patients undergoing treatment and monitoring of their lipid profiles.

\section{Acknowledgement}

None.

\section{Conflict of Interest}

No conflict of interest.

\section{References}

1. Crook MA (2000) Near patient testing and pathology in the new millennium. Journal of Clinical Pathology 53: 27-30.

2. Kilgore ML, Steindel SJ, Smith JA (1998) Evaluating stat testing options in an academic health centre: therapeutic turnaround time and staff satisfaction. Clin Chem 44 (8): 1597-1603.

3. Rainey PM (1998) Outcomes assessment for point-of-care testing. Clin Chem 44(8): 1595-1596.

4. Price CP (2001) Regular review: Point of care testing. BMJ 322: 12851288.

5. Hobbs R (1996) Near patient testing in primary care. BMJ 312: 263-264.

6. Price CP (2003) Delivering clinical outcomes. Point-of-Care-Journal of Near Patient Testing and Technology 2(3): 151-157.

7. Cottrell E, Chambers R, O'Connell P (2012) Using simple telehealth in primary care to reduce blood pressure; a service evaluation. BMJ Open 2: e001391.

8. Klonoff DC (2007) Benefits and Limitations of self-monitoring of blood glucose. J Diabetes Sci Technol 1: 130-132.

9. Pluddermann A, Thompson M, Price CP, Wolstenholme J, Heneghan C
(2012) Point of care testing for the analysis of lipid panels. Br J Gen Pract 62 (596): e224-e226.

10. Centre for Evidence Based Purchasing. CEO catalogue search Department of Health, London, UK.

11. Dale RA, Jensen LH, Krantz MJ (2008) Comparison of two point of care lipid analyzers for use in global cardiovascular risk assessment. Ann Pharmacother 42 (5): 633-639.

12. Shephard MD, Mazzachi BC, Shephard AK (2007) Comparative performance of two point of care analyzers for lipid testing, Clin Lab 53 (9-12): 561-566.

13. Scafoglieri A, Tresignie J, Provyn S, Clarys JP, Bautmans I (2012) Reproducibility, accuracy and accordance of Accutrend® Plus for measuring circulating lipid concentrations in adults. Biochemia Medica 22(1): 100-108.

14. Yun K, Lee J, Choi J, Song IU, Chung YA (2019) Smartphone based point of care lipid blood test performance evaluation compared with a clinical diagnostic laboratory method.

15.(1988) National Cholesterol Education Program Laboratory Standardization Panel. Current status of blood cholesterol measurement in clinical laboratories in the US. Clin Chem 34: 193-201.

16.(1995) National Cholesterol Education Program Laboratory Standardization Panel. Recommendations for measurement of highdensity lipoprotein cholesterol; executive summary. Clin Chem 41: 1427-1433.

17. Whitehead SJ, Ford C, Gama Rousseau (2013) A combined laboratory and field evaluation of the Cholestech LDX and CardioChek PA point of care testing lipid and glucose analysers. Ann Clin Biochem 51(1): 54-67.

18. Bolodeoku J, Pinkney S (2019) Imprecision evaluation of selfmonitoring of blood cholesterol (SMBC) handheld point of care testing devices:Elemark ${ }^{\mathrm{TM}}$ and CardioChek PA. Ann Clin Lab Res 7(1): 289-290.

19. Rapi S, Bazzini C, Tozzetti C, Sbolci V, Modesti PA (2009) Point of care testing of cholesterol and triglycerides for epidemiologic studies: evaluation of the MultiCare in system. Translational Research 153 (2): 71-76.

20. Hammond J, Wentz P, Statland BE, Phillips JC, Winkel P (1976) Daily variation of lipids and hormones in sera of healthy subjects. Clinica Chimica Acta 73 (2): 347- 352.

21. Demacker PNM, Schade RWB, Jansen RTP, Laar AV (1982) Intraindividual variation of serum cholesterol triglycerides and high-density lipoprotein cholesterol in normal humans. Atherosclerosis 45(3): 259266.

22. Gidding SS, Stone NJ, Bookstein LC, Laskarzewski PM, Stein EA (1998) Month to month variability of lipids, lipoproteins and apolipoproteins and the impact of acute infection in adolescents. The Journal of Pediatrics 133(2): 242-246

23. Bookstein L, Gidding SS, Donovan M, Smith FA (1990) Day to day variability of serum cholesterol, triglyceride and high-density lipoprotein cholesterol levels. Arch Intern Med 150(8): 1653-1657.

24. Bolodeoku J (2018) Biological Variation of Self-Monitoring of Blood Cholesterol (SMBC) Using Portable Handheld Point of Care Testing Devices: 3in1, Cardio chek PA and Elemark. Curr Trends Med Diagn Meth 2018: CTMDM-106.

25. Alkouli MA, Carry BJ, Jarrett H, Sirna SJ (2013) Management of hypercholesterolaemia utilizing a home lipid monitoring system; preliminary findings. J Clin Lipid 7(3): 254 -255. 
ISSN: 2574-1241

DOI: 10.26717/BJSTR.2019.23.003967

Bolodeoku J. Biomed J Sci \& Tech Res

(c) (P) This work is licensed under Creative

Submission Link: https://biomedres.us/submit-manuscript.php

$\begin{array}{ll}\text { BIOMEDICAL } & \text { Assets of Publishing with us } \\ \text { RESEARCHES } & \text { - Global archiving of articles } \\ \text { - Immediate, unrestricted online access }\end{array}$

